CADENA, Pablo; LETELIER, Leonardo. "Determinantes de los Delitos de Mayor Connotación Social en la Región Metropolitana. Análisis en base a un modelo de regresión logística".

Polit. crim. Vol. 13, № 26 (Diciembre 2018) Art. 14, pp. 1170-1189.

[http://www.politicacriminal.cl/Vol_13/n_26/Vol13N26A14.pdf]

\title{
Factores determinantes de los Delitos de Mayor Connotación Social en la Región Metropolitana. Análisis en base a un modelo de regresión logística ${ }^{1}$
}

\section{Determining Factors of High Social Connotation Crimes in the Metropolitan Region. A logistic model analysis.}

\author{
Pablo Cadena Urzúa \\ Magíster en Gestión y Políticas Públicas, Facultad de Ciencias físicas y Matemáticas, \\ Universidad de Chile. Doctorando en Derecho, Ciencia Política y Criminología, \\ Universidad de Valencia, España. \\ pablo.cadena@ing.uchile.cl
}

Leonardo Letelier Saavedra

Profesor asociado y Director de la Escuela de Postgrado del Instituto de Asuntos Públicos de la Universidad de Chile. Doctor en Economía, Universidad de Sussex, Reino Unido.

lletelie@iap.uchile.cl

\section{Resumen}

Las iniciativas enfocadas sólo en acciones de control policial, si bien elevan la percepción de seguridad, no actúan sobre las causas multifactoriales de un problema social dinámico y complejo. Por ende, se deben desarrollar medidas de prevención y de control, las que requieren la participación activa, sinérgica y coordinada de todos los actores involucrados en materia de seguridad pública, para disminuir los factores de riesgo que derivan en el actuar criminal. El objetivo de este trabajo es medir la incidencia de factores espaciales, temporales y elementos de contexto que caracterizan a las comunas de la Región Metropolitana de Chile (2014), en la probabilidad de ocurrencia de delitos específicos en el contexto de todos los delitos registrados en los casos de mayor connotación social. Entre las principales contribuciones del presente estudio -el que cuenta con más de 300 mil casos policiales-, se encuentran la individualización de las comunas más expuestas a ser víctimas de determinados delitos. Se proporciona también información analítica que permite cambiar el paradigma de patrullajes sin fundamento, por uno basado en un modelo que permite optimizar el uso de los recursos policiales.

Palabras clave: Prevención del delito, factores de la criminalidad, factores condicionantes de la victimización, factores sociales de la criminalidad, modelos econométricos.

\footnotetext{
${ }^{1}$ Una primera versión de este trabajo se presentó como tesis para obtener el Grado Académico de Magíster en la Facultad de Ciencias Físicas y Matemáticas (Departamento de Ingeniería Industrial) de la Universidad de Chile.
} 


\begin{abstract}
Initiatives only focused on police control actions, while raising the perception of security, do not act on the multifactorial causes of a dynamic and complex social problem. Therefore, prevention and control measures must be developed, which require the active, synergistic and coordinated participation of all the actors involved in public safety in order to reduce risk factors that result in criminal activity. This research is intended to measure the incidence of spatial, temporal and contextual factors that characterize the communes of the Metropolitan Region of Chile (2014) as regard the probability of occurrence of specific crimes in the context of all recorded cases of greater social connotation. Among the main contributions of this study - which is based on more than 300 thousand police cases - is the individualization of the communes most exposed to specific crimes. Analytic information is also provided in order to change the paradigm of groundless patrols, by one based on a model that allows the optimization of police resources.
\end{abstract}

Key words: Crime prevention, factors of criminality, factors determining victimization, social factors of criminality, econometric models.

\title{
Introducción
}

El ítem seguridad pública (delincuencia, asaltos y robos), históricamente se encuentra entre las principales inquietudes de las personas. Prueba de ello, es que según cifras de la última encuesta del Centro de Estudios Públicos (CEP) de agosto de 2016, dicho factor se ubica en el primer lugar de las preocupaciones que más afectan a la ciudadanía chilena, con un 52\%, seguida por salud y corrupción.

Diversos enfoques teóricos se han desarrollado sobre el origen del delito, dentro de los esfuerzos para explicar el fenómeno destacan la teoría de oportunidad y enfoque ecológico del crimen, teorías psicosociales y sociológicas, teoría epidemiológica y la teoría económica del delito. En esta última se centra el desarrollo de la presente investigación, siendo sin lugar a dudas uno de sus principales exponente el Premio Nobel de Economía (1992) Gary Becker ${ }^{2}$. Este enfatiza que la "oferta" de delitos tiene dos determinantes básicos, los cuales son evaluados por el potencial delincuente al momento de evaluar la decisión de cometer la falta. Estos son: (1) la probabilidad de ser aprehendido y (2) el tipo de castigo asociado a la falta. Si uno o ambos factores presentan debilidades en su diseño, o en la forma en que el delincuente las evalúa durante la situación pre-delito, ello promoverá la comisión de más delitos. En el contexto de su modelo, Becker analiza el problema pensando en el efecto que las variables explicativas tienen sobre los beneficios netos asociados a la comisión de un determinado delito ${ }^{3}$.

La delincuencia, indudablemente ha sido un tema prioritario al momento de discutir y diseñar las políticas públicas, todas las cuales requieren información adecuada para su

\footnotetext{
2 BECKER, Gary, “Crime and Punishment: An Economic Approach”, Journal of Political Economy”, No 76, (1968), pp.169-217.

${ }^{3}$ Ver por ejemplo: RIVEROS, Luis, "El enfoque económico del delito", Revista Académica de la Academia de Ciencias Policiales, Carabineros de Chile, nº 47 (2008), pp. 25-38.
} 
CADENA, Pablo; LETELIER, Leonardo. "Determinantes de los Delitos de Mayor Connotación Social en la Región Metropolitana. Análisis en base a un modelo de regresión logística".

debida implementación. En este sentido, la XI versión de la "Encuesta Nacional Urbana de Seguridad Ciudadana" (ENUSC) realizada por el Instituto Nacional de Estadísticas de Chile (INE) durante el año 2014, evidenció que el 25,0\% de los hogares ha sido víctima de algún delito durante los últimos doce meses. Por otro lado, los hogares victimizados que denunciaron al menos un delito en los últimos doce meses representan un 40,4\% en 2014. Junto con la medición de victimización, la ENUSC mide la percepción de inseguridad y reacción frente al delito. En esta dimensión, se observa que entre 2013-2014 la proporción de personas que percibe que la delincuencia aumentó en el País durante los últimos doce meses se incrementó en 8,9 puntos porcentuales entre ambos años. Al mismo tiempo, la proporción de personas que creen que serán víctimas de delito en los próximos doce meses aumentó en 5,5 puntos porcentuales. Al comparar el período de enero a marzo del año 2015 respecto del mismo período del 2014, los delitos de mayor connotación social a nivel nacional presentaron una disminución del $-1,8 \%$, cuya frecuencia absoluta corresponde a una baja de 2.567 casos delictuales durante el año 2015 respecto al 2014. No obstante esta cifra, los delitos que presentan un aumento importante durante este periodo son Otros Robos con Fuerza (8,2\%), Robo en Lugar No Habitado $(6,6 \%)$ y Robo con Intimidación $(3,4 \%)$. Las mayores bajas se presentan en los delitos de Homicidio (-8,2\%), Lesiones ($7,0 \%)$ y Robo por Sorpresa $(-6,1 \%)$.

El presente trabajo pretende determinar la probabilidad de ocurrencia de delitos específicos, tomando como base el conjunto de todos los delitos de mayor connotación social ocurridos en las comunas de la Región Metropolitana. La referida estimación se basa en la información histórica proveniente de registros concretos de Carabineros de Chile ${ }^{4}$, la cual permite conocer el tipo de delito, el lugar de ocurrencia, y la fecha de su ocurrencia. Complementariamente, se utilizan datos de contexto provenientes de la encuesta CASEN $^{5}$ (2009 y 2013), y el Sistema de Información Municipal del Ministerio del Interior. A partir de lo anterior se estima un modelo logistico para cada tipo de delito, cuyas variables explicativas incluyen, entre otros elementos, factores especiales o ecológicos y temporales vinculados al delito en cuestión.

El resto de este trabajo se organiza como sigue. La sección 1 aborda los enfoques teóricos sobre el origen del delito. La sección 2 discute el concepto de Actividad Predictiva Policial. La sección 3 revisa la evidencia empírica disponible en Chile. La sección 4 explica la metodología y plantea las hipótesis. Los resultados son presentados en la sección 5. La discusión y conclusiones se abordan en la sección 6.

\section{Los enfoques teóricos sobre el origen del delito}

Uno de los aspectos en los que más ha incidido la criminología tradicional ha sido en el tratamiento del delito desde el punto de vista clínico. Sin embargo, cada vez son más importantes las líneas de investigación que incluyen los aspectos sociales y los económicos entre las variables que ejercen influencia en las tasas del delito, sobre todo a raíz de los

\footnotetext{
${ }^{4}$ Carabineros de Chile asume aproximadamente el $95 \%$ de los procedimientos policiales a nivel nacional, el 5\% restante se divide entre la Policía de Investigaciones de Chile y las Fiscalías.

5 Encuesta de Caracterización Socioeconómica Nacional, es una encuesta a nivel nacional, regional y comunal, que realiza el Gobierno de Chile desde el año 1985.
} 
trabajos sobre economía del delito de Gary Becker, y de las posteriores ampliaciones realizadas por Ehrlich ${ }^{6}$. Becker intenta cuantificar los recursos y la magnitud del castigo necesarios para hacer cumplir la Ley. Para esto, este autor enfatiza que los crímenes provocan externalidades a los individuos, y por tanto existe una perdida social asociada al crimen. Para explicar las motivaciones que están detrás de que un individuo cometa un delito, Becker deriva lo que denomina la "oferta de delitos". Esta tendría dos determinantes básicos que el individuo considera al momento de delinquir, los cuales son; i) la probabilidad de ser aprehendido y ii) el tipo de castigo. Dicha oferta refleja el hecho que para algunos individuos su utilidad esperada es mayor si dedican recursos y tiempo a actividades delictivas que a actividades legales. Así, la coexistencia de personas que actúan como delincuentes y personas que no lo son reflejarían diferencias entre sus costos y beneficios ${ }^{7}$.

El análisis económico del delito parte de la concepción utilitarista del individuo, la cual se expresa en un marco de restricciones institucionales y valores esperados de los costos y beneficios de las acciones individuales. Así, los delincuentes no son contemplados como individuos desviados e irracionales, sino como personas normales, cuyo objetivo es maximizar su utilidad individual. En esta misma línea, el sistema judicial sería un "mercado" que podría alcanzar la combinación deseada entre seguridad (beneficio) y el gasto necesario para garantizar el imperio de la Ley (costo). La visión del delito así entendida, tiene su origen en la hipótesis original de Jeremy Bentham ${ }^{8}$, según la cual el beneficio del crimen es lo que lleva a los hombres a delinquir, y que el sufrimiento del castigo era la fuerza con la que se restringía el mismo ${ }^{9}$.

Un enfoque alternativo es la denominada "Criminología Ambiental". Esta fue desarrollada en la década de 1980 por el matrimonio Paul y Patricia Brantingham ${ }^{10}$, poniendo el foco de estudio criminológico sobre los factores ambientales o de contexto que pueden influir en la actividad criminal. La Criminología Ambiental plantea que los eventos delictivos deben entenderse como una confluencia de infractores, víctimas u objetivos del delito, y normativas legales, en escenarios específicos, ocurriendo en un momento y lugar concreto. Esto significa que un análisis completo del delito tiene cuatro dimensiones; i) la dimensión legal, ii) la dimensión del infractor, iii) la dimensión de la víctima/objetivo, y iv) una dimensión espacio-temporal. Estas dimensiones han de comprenderse e interpretarse sobre un telón de fondo histórico y situacional complejo, de características sociales, económicas, políticas, biológicas y físicas, que establecen el contexto en el que están contenidas las dimensiones del delito.

\footnotetext{
${ }^{6}$ EHRLICH, Isaac, "Participation in illegitimate activities: A theoretical and empirical investigation", Journal of Political Economy, $\mathrm{N}^{\circ} 81$ (1973), pp. 521-565.

${ }^{7}$ Esto puede ser también entendido por el hecho de que los individuos tienen actitudes diversas frente al riesgo.

${ }^{8}$ Filósofo inglés autor del "utilitarismo" (1748-1832).

9 Ver por ejemplo; EIDE, Erling, "Economics of criminal behavior", Encyclopedia of Law and Economics 8100, 1999.

10 BRAnTINGHAM, Paul J.; BRANTINGHAM Patricia L., "Environmental Criminology", Sage Publications, 1981.
} 
CADENA, Pablo; LETELIER, Leonardo. "Determinantes de los Delitos de Mayor Connotación Social en la Región Metropolitana. Análisis en base a un modelo de regresión logística".

\section{Actividad Policial Predictiva}

Cuando hablamos de "predecir el crimen", sin lugar a dudas evocamos una imagen futurista y cinematográfica similar a la cinta Minority Report dirigida por Steven Spielberg, pero ya lo decía la tercera ley de Arthur C. Clarke: "Toda tecnología lo suficientemente avanzada es indistinguible de la magia". Sin embargo, en la teoría criminologíca el término "precrime" no es nuevo, puesto que cimienta sus orígenes en la escuela positivista de fines del Siglo XIX, principalmente en la idea del médico italiano y criminólogo Ezechia Marco Lombroso $^{11}$ quien postulaba que hay personas que nacen siendo criminales. Hoy en día, con menos ficción y mayor rigor científico, la predicción del crimen ha experimentado significativos avances, principalmente en países como Estados Unidos e Inglaterra, en los cuales se ha hecho uso extensivo de algoritmos y estimaciones econométricas (criminología algorítmica) que permiten pronosticar con altos niveles de confianza, donde y cuando se producirán los delitos. Dentro de los softwares de predictive policing más conocidos se encuentra el Predpol, el que se utiliza en más de media docena de ciudades norteamericanas. Otro sistema con el mismo fin es Hunchlab de la empresa americana Azavea, además del Risk Terrain Modeling o RTM, diseñado por los académicos Joel Caplan y Leslie Kennedy de la Universidad de Rutgers en Nueva Jersey. A los anteriores programas se suman otros proyectos como Promap, Odissey, IPol e Indect, entre otros que tienen como objetivo el de reducir el crimen utilizando grandes conjuntos de datos o Big Data. En nuestro país, el Centro de Análisis y Modelamiento en Seguridad (CEAMOS) de la Universidad de Chile, trabaja desde 2008 en el desarrollo de algoritmos matemáticos para abordar diversos problemas de seguridad, dándole un enfoque científico a la labor policial, siendo líder regional en la materia.

\section{La evidencia empírica en Chile}

Un estudio pionero es el desarrollado por Rivera, Núñez y Villavicencio ${ }^{12}$, el cual está basado en datos regionales. En él se muestra que los delitos con potenciales beneficios económicos, tales como Robo, drogas y Estafa, tienen su origen principalmente en motivaciones económicas e incentivos negativos tales como la misma fuerza policial. Por el contrario, delitos en los cuales hay agresión física de por medio (Violación, Homicidio y Violencia), responden principalmente a factores de contexto y elementos ajenos a los incentivos económicos. Una versión ampliada de este análisis confirma estos resultados ${ }^{13}$. En esta misma línea, la fortaleza de los factores institucionales parece influir negativamente en el crimen de acuerdo el estudio de Ruiz et. al. ${ }^{14}$. Respecto de los elementos de contexto físico, cierta evidencia indica que las farmacias y paseos peatonales aumentan la

11 Conocido con el seudónimo de Cesare Lombroso (1835-1909), es el autor del llamado "positivismo criminológico". Postulaba que pueden ser reconocidas por sus características físicas, pudiendo presagiar quien cometería delitos.

12 MOLINA, Oscar, NÚÑEZ, Javier, RIVERA, Jorge y VILLAVICENCIO, Xavier, Determinantes Socioeconómicos y Demográficos del Crimen en Chile. Evidencia desde un panel de datos de las Regiones de Chile", Estudios de Economía, No 30 (2003), pp. 55-85.

13 GUTIÉRREZ, Mauro, NÚÑEZ, Javier y RIVERA Jorge, "Caracterización socioeconómica y espacial de la criminalidad en Chile", Revista Cepal, No 98, (2009) pp. 165-180.

14 RUIZ, Paulina, CEA, Macarena, RODRÍGUEZ, Carlos, MATUS, Jean Pierre, "Determinantes de la criminalidad: Análisis de Resultados", Política Criminal, n³, Documento 1 (2007) pp.1-80. 
probabilidad de delito en Chile (Jofré y Paz $)^{15}$. Le siguen en importancia, lugares de comercio masivo y bancos. Respecto del contexto social, un análisis realizado con datos regionales entre 1990 y 2008 para los casos de Robo con Fuerza, Robo con Violencia y Hurto $^{16}$, sugiere que junto a los factores disuasivos vinculados a la eficacia policial, los factores sociodemográficos más recurrentes en el territorio, tales como consumo de drogas, escolaridad promedio de los jóvenes y otros semejantes, son elementos importantes en el origen del crimen. Respecto de la capacidad predictiva de las estimaciones econométricas, un trabajo de Toledo $^{17}$ con datos para la comuna de Santiago realizado con vectores autoregresivos (VAR), concluye que dicha técnica ofrece predicciones razonablemente certeras solo en algunos delitos, con errores de predicción cercamos al 27\%, los cuales son similares para estudios semejantes en Estados Unidos e Inglaterra. El uso de metodologías alternativas con fines predictivos refuerza esta evidencia, y sugiere que al menos parcialmente, el conjunto de factores situacionales del delito permite anticipar su ocurrencia con un razonable margen de certidumbre ${ }^{18}$.

\section{Hipótesis y Metodología}

\subsection{Hipótesis del Trabajo}

Existe una multiplicidad de orígenes de los factores de riesgo y que contribuyen a la complejidad del estudio del fenómeno criminal, algunos de los cuales han sido considerados en la presente investigación. De acuerdo a Trudel y Puentes-Neuman ${ }^{19}$, los factores de riesgo delictual pueden ser clasificados en 6 ámbitos de procedencia, de acuerdo a un continuo que va desde el nivel individual hasta el nivel sociocultural:

- Factores individuales

- Factores familiares (ej. violencia intrafamiliar)

- Factores ligados al grupo de iguales

- Factores escolares (ej. deserción escolar)

- Factores sociales o comunitarios

- Factores socioeconómicos y culturales

15 JOFRÉ, María Paz, “Análisis del fenómeno delictual utilizando un modelo de regresión logística en base a atributos". Santiago, Chile: Universidad de Chile - Facultad de Ciencias Físicas y Matemáticas, 2011.

16 DE LA FUENTE, Hanns; MEJÍAS, Claudia y CASTRO K., Pía, "Análisis econométrico de los determinantes de la criminalidad en chile”, Política Criminal, vol. 6, nº 11, doc. 1 (2011), pp. 192 - 208.

17 TOLEDO, Rodrigo, "Métodos econométricos para el pronóstico de delitos en el gran Santiago". Santiago, Chile: Universidad de Chile - Facultad de Economía y Negocios, 2005.

18 Ver por ejemplo: (i) FLORES, Paulina, "Modelación y predicción de focos de criminalidad basada en modelos probabilísticos". Santiago, Chile: Universidad de Chile - Facultad de Ciencias Físicas y Matemáticas, 2014, (ii) OBRECHT Ihl, Paz , "Predicción de crimen usando modelos de Markov ocultos". Santiago, Chile: Universidad de Chile - Facultad de Ciencias Físicas y Matemáticas, 2014.

19 TRUDEL, Marcel; PUENTES-NEUMAN, Guadalupe, "The contemporary concepts of at risk children: theoretical models and approaches in the early years", Pan Canadian Education Research Agenda Symposium, 2000. 
CADENA, Pablo; LETELIER, Leonardo. "Determinantes de los Delitos de Mayor Connotación Social en la Región Metropolitana. Análisis en base a un modelo de regresión logística".

Además, debemos sumar un importante comportamiento riesgoso como lo es el consumo de drogas. El referido estudio plantea como hipótesis central, que tanto el lugar de ocurrencia del delito, como las variables temporales y de contexto comunal, son elementos que añaden gran poder explicativo al problema. En dicho sentido, el presente trabajo innova en la dirección de estimar un modelo que permite identificar la incidencia a nivel comunal de los factores antes mencionados, el cual tiene efectos potencialmente significativos en la comisión de distintos tipos de delitos, en este caso aquellos denominados "de mayor connotación social".

Con el fin de cuantificar la influencia de las variables y encontrar los factores determinantes de los delitos de mayor connotación social, se utilizará un modelo Logístico. Se utilizaron datos de panel del año 2014. Estos datos corresponden a los registros del "Departamento de Análisis Criminal" de Carabineros de Chile. La unidad de análisis será el área correspondiente a la comuna en el área geográfica de la Región Metropolitana. La investigación propuesta busca innovar respecto a estudios previos sobre la materia en el hecho de utilizar una base comprehensiva y detallada de los delitos de "mayor connotación social" ocurridos en el 2014 en la región metropolitana, la cual contiene elementos particulares del delito, cuya incidencia no han sido debidamente explorada en trabajos previos.

\subsection{Procedimiento de estimación del Modelo}

Nuestro modelo básico se puede resumir a partir de la Ec.1. En ella se han separado dos bloques de variables. En la primera se incluye un conjunto de variables que reflejan los incentivos que mueven a los delincuentes, los cuales en este caso están asimilados al concepto de "oportunidad". Entenderemos por tal el conjunto de factores temporales y de localización que hacen más (menos) probable la ocurrencia de un delito específico, sobre los cuales el delincuente tiene un "Control", puesto que alije el lugar, la hora y la fecha específica. En la tabla 2 se especifica el conjunto de tales factores con el signo esperado. Respecto del contexto, entenderemos por tal, el conjunto de factores ambientales en donde se desarrolla el delito, en los cuales se considera el tipo de municipio en sus dimensiones económicas y sociales. El signo esperado y la significancia de cada variable en el análisis de regresión, depende del tipo de delito en cuestión. Si bien esto es genéricamente válido, hay algunos casos en los cuales dicho signo tiene un valor incierto. En este trabajo se plantea la hipótesis (confirmada por estudios previos) de que: i) la densidad poblacional incide positivamente en la ocurrencia de los delitos de Homicidio, Hurto, Lesión, Violación y Robo con Violencia; ii) el hacinamiento afecta positivamente la tasa de Homicidios, Lesiones, Violación y Robo con Violencia; iii) las áreas verdes en las comunas contribuyen positivamente a reducir el delito de Robo con Violencia iv) la ruralidad favorece la ocurrencia de todos los delitos en estudio, con excepción del Robo con Fuerza ; y por último v) la inversión promedio por habitante que llevan a cabo las comunas es una variable proxy del esfuerzo del municipio por mejorar el entorno y las condiciones de vida de la comuna. Si dicho entorno fuese relevante, lo anterior debiese afectar negativamente la ocurrencia de delitos.

$$
P \text { ? } i \text { ? }=F X \text { ? } i \text { ? }, Z \text { 目 } i \text { ? }+\mu \text { ? } i \text { ? } E c .1
$$


Pi es la probabilidad de ocurrencia de un delito tipo " $i$ ", $X_{i}$ es el conjunto de características específicas del delito, y $Z_{i}$ es el contexto en que se produce el delito.

\begin{tabular}{|c|c|c|c|c|c|c|c|}
\hline & Nombre de la Variable & Homicidio & Hurto & Lesión & Violación & $\begin{array}{c}\text { Robo } \\
\text { con } \\
\text { Fuerza }\end{array}$ & $\begin{array}{l}\text { Robo con } \\
\text { Violencia }\end{array}$ \\
\hline \multirow{4}{*}{ 递 } & DIA & + & + & + & + & + & + \\
\hline & MES & $?$ & + & + & $?$ & + & + \\
\hline & COMUNA & + & + & + & + & + & + \\
\hline & DENSIDAD & + & + & + & + & - & + \\
\hline \multirow{4}{*}{ 党 } & HACINAMIENTO & + & - & + & + & - & + \\
\hline & AREAS VERDES POR HABITANTE & $?$ & + & $?$ & $?$ & + & - \\
\hline & RURALIDAD & $?$ & + & + & + & - & + \\
\hline & $\begin{array}{l}\text { INVERSIÓN PROMDIO POR HABITANTE } \\
\text { (IPP) }\end{array}$ & - & + & - & $?$ & - & - \\
\hline
\end{tabular}

\section{Donde:}

- Densidad: Superficie comunal (ha) / hab

- Hacinamiento: Es el cociente entre el número de personas residentes en la vivienda y el número de dormitorios de la misma. Se considera dormitorio el total de habitaciones destinadas a dormitorio en una vivienda, ya sea que sea de uso exclusivo o uso compartido.

- Áreas verdes por habitante: $\mathrm{m} 2$ de áreas verdes con mantenimiento / hab

- Ruralidad: El porcentaje de la población comunal que habita en asentamientos definidos como rurales, según los criterios oficiales definidos por el Instituto Nacional de Estadísticas (INE).

- Inversión promedio por habitante (IPP): Inversión pública de la comuna M\$/hab

El estudio se llevó a cabo en base a datos del año 2014 en la Región Metropolitana de Santiago. Esta limita al norte y al oeste con la Región de Valparaíso, al este con Argentina y al sur con la Región del Libertador General Bernardo O'Higgins. Cuenta con una superficie de 15.403,2 km², y una población que supera los 6 millones de habitantes, lo que equivale al $40,1 \%$ de la población nacional. Para efectos del gobierno y administración interior, la referida región se divide en 6 provincias (Santiago, Chacabuco, Cordillera, Maipo, Melipilla, Talagante) y estas a su vez en 52 comunas, siendo la capital regional la ciudad de Santiago. Los datos espaciales y elementos de contexto que caracterizan a las comunas en estudio provienen de la encuesta CASEN (2009 y 2013) y la base SINIM del Ministerio del Interior.

La información respecto al momento y lugar de ocurrencia de los delitos considerados en la presente investigación, se obtuvo de la Dirección Nacional de Orden y Seguridad de Carabineros de Chile, específicamente del Departamento de Análisis Criminal mediante el Sistema de Automatización de Unidades Policiales (AUPOL). El AUPOL consiste en un 
CADENA, Pablo; LETELIER, Leonardo. "Determinantes de los Delitos de Mayor Connotación Social en la Región Metropolitana. Análisis en base a un modelo de regresión logística".

sistema informático que se sustenta en los registros que ingresan los Carabineros de servicio en las Unidades Policiales al momento de conocer una denuncia. Esta incluye 374.751 casos policiales registrados en el año 2014.

En cuanto a los delitos seleccionados para la investigación, se escogieron aquellos que se caracterizan por ser los de mayor frecuencia, violencia e impacto en la victimización de la ciudadanía, es decir, los denominados "Delitos de Mayor Connotación Social"20, que según la División de Seguridad Ciudadana del Ministerio del Interior y Seguridad Pública, son el robo con violencia (robo con violencia propiamente tal, robo con intimidación y robo por sorpresa); robo con fuerza en las cosas (sea o no en lugar habitado); hurto, lesiones; violación y homicidio. La base utilizada en el presente estudio incluye factores espaciales y temporales, además de las características de cada una de las comunas de la región metropolita, para cada uno de los delitos de "mayor connotación social" acaecidos durante el año 2014.

La estimación realizada en este trabajo exige abordar dos desafíos metodológicos importantes. El primero es el hecho de que los datos de delitos utilizados no tienen contrafactual $^{21}$, puesto que se trata de la base de "registros de delitos", lo cual nos impide la estimación de una "probabilidad de ocurrencia" como tal. En dicho contexto, cabe aclarar que, al utilizar la base de todas las denuncias registradas, lo que haremos en este caso, es estimar la "probabilidad de que un delito específico haya ocurrido", pero en el marco de la población de denuncias antes referidas y no respecto de un escenario sin delito bajo condiciones equivalentes.

El segundo desafío, es que el modelo presentado contiene las dificultades clásicas de un "sesgo de simultaneidad", lo cual puede ser un problema de la mayor importancia si incluimos la dotación policial como variable explicativa ${ }^{22}$. El problema es que los delitos (DEL) están determinados por la dotación policial (DP) y viceversa, lo cual supone una causalidad en ambas direcciones. En concordancia con lo anterior, lo que deseamos saber es qué factores afectan los delitos, y no necesariamente qué dotación policial se requiere dado un cierto volumen de delitos. Por lo anterior, transformaremos la "forma estructural" del modelo, en la cual los delitos dependen de la dotación policial (Ecs 2, 3), en la llamada "forma reducida" (Ec. 4), la cual resulta de resolver el sistema de ecuaciones antes mencionado, dejando solo las variables exógenas explicativas en el lado derecho de la ecuación de delitos. De esta forma, podemos omitir la variable DP de entre las variables explicativas.

Es importante destacar que el modelo se estima en base a los casos policiales registrados, obviando la cifra de no denuncia o "cifra negra", que según la ENUSC del año 2014

\footnotetext{
${ }^{20}$ Delitos de Mayor Connotación Social (DMCS): Homicidio, Hurto, Lesiones, Violación, Robo con fuerza (Robo de accesorios de vehículos; Robo de vehículo motorizado; Robo en lugar habitado; Otros Robos con fuerza), Robo con Violencia (Robo con intimidación; Robo con Violencia; Robo por sorpresa, Otros Robos con Violencia)

${ }^{21}$ Hace referencia a un evento o acontecimiento que no ha sucedido en el universo actualmente observado por la investigación, pero que podría haber ocurrido.

${ }^{22}$ La variable dependiente puede ser parte de un sistema de ecuaciones simultáneas.
} 
Polit. crim. Vol. 13, № 26 (Diciembre 2018) Art. 12, pp. 1170-1189.

[http://www.politicacriminal.cl/Vol_13/n_26/Vol13N26A12.pdf]

alcanzó el 59,6\% en los DMCS. Para estos efectos, tal cifra será considerada como un "error sistemático" 23 , por lo cual no tiene incidencia en la calidad de los datos utilizados, ni en las propiedades estadísticas del modelo propuesto.

Forma estructural ${ }^{24}$ :

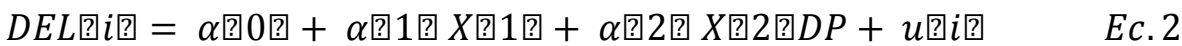

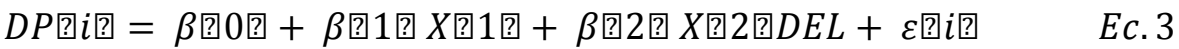

Forma Reducida (Reemplazando la Ec. 2 en Ec. 3):

$D E L$ 目 $i$ ? $=\delta \varphi+\pi X$ 目 $i$ ? $+\omega$ 目 $i$ ? $\quad E c .4$

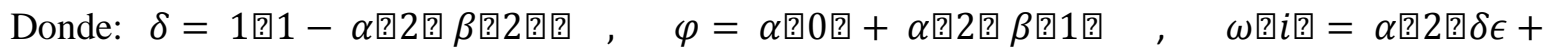
$\delta \mu$

El modelo anterior (Ec. 4) se estima en base a una regresión logística binaria, mediante el método de máxima verosimilitud (ver sección siguiente).

\section{Resultados}

\subsection{Estimación del Modelo}

Una vez estimado los coeficientes, se verificó si el modelo predice de manera adecuada las variables dependientes. Para evaluar la bondad del modelo se utiliza el logaritmo del cociente de verosimilitud, arrojando los siguientes resultados por delito:

\section{Tabla $\mathbf{n}^{\circ} 1$}

\begin{tabular}{|c|c|c|c|c|c|}
\hline Medida de bondad de ajuste & Homicidio & Hurto & Lesión & Violación & Robo con fuerza Robo con violencia \\
\hline Pseudo R2 & 0.0651 & 0.3906 & 0.0751 & 0.0671 & 0.0831 \\
\hline
\end{tabular}

Se puede apreciar que los delitos que mejor se ajustan son el Hurto y el Robo con violencia, en los cuales la proporción de la variación explicada por el modelo supera el 20\%, llegando al 39\% en el caso de los hurtos. Lo anterior permite anticipar que el grueso de los factores responsables de los Robos con fuerza, las Lesiones, los Homicidios y las Violaciones,

\footnotetext{
${ }^{23}$ Es aquel que se origina de igual modo en todas las mediciones que se realizan en una dimensión.

${ }^{24}$ Un modelo estructural representa relaciones de causalidad.
} 
CADENA, Pablo; LETELIER, Leonardo. "Determinantes de los Delitos de Mayor Connotación Social en la Región Metropolitana. Análisis en base a un modelo de regresión logística".

responden a factores no observables a través de los datos. La tabla $n^{\circ} 2$ presenta los resultados de las regresiones logísticas. ${ }^{25}$

Tabla no 2 Regresión logística

\begin{tabular}{|c|c|c|c|c|c|c|}
\hline VARIABLES & $\begin{array}{l}\text { DELITO } \\
\text { HOMICIDIO }\end{array}$ & $\begin{array}{l}\text { DELITO } \\
\text { HURTO }\end{array}$ & $\begin{array}{l}\text { DELITO } \\
\text { LESION }\end{array}$ & $\begin{array}{c}\text { DELITO } \\
\text { VIOLACION }\end{array}$ & $\begin{array}{l}\text { DELITO } \\
\text { ROBO CON } \\
\text { FUERZA }\end{array}$ & $\begin{array}{l}\text { DELITO } \\
\text { ROBO } \\
\text { VIOLENCIA }\end{array}$ \\
\hline DENSIDAD & $\begin{array}{c}2.38 \mathrm{e}-05 \\
(1.48 \mathrm{e}-05)\end{array}$ & $\begin{array}{l}-9.29 \mathrm{e}-07 \\
(1.70 \mathrm{e}-06)\end{array}$ & $\begin{array}{c}6.32 \mathrm{e}-07 \\
(1.61 \mathrm{e}-06)\end{array}$ & $\begin{array}{l}4.06 \mathrm{e}-05 * 4 * \\
(9.23 \mathrm{e}-06)\end{array}$ & $\begin{array}{c}-4.58 \mathrm{e}-05 * * * \\
(1.27 \mathrm{e}-06)\end{array}$ & $\begin{array}{l}4.40 \mathrm{e}-05 * 4 * \\
(1.57 \mathrm{e}-06)\end{array}$ \\
\hline HACINAMIENTO & $0.112^{* * *}$ & $-0.031 * * *$ & $0.042^{* 4 *}$ & $0.047^{* * * *}$ & $-0.057^{4 * 4}$ & $0.036^{*+*}$ \\
\hline AREAS_VERDES_POR HABITANT & $\begin{array}{l}(0.012) \\
0.044\end{array}$ & $(0.001)$ & $\begin{array}{l}(0.001) \\
-0.005\end{array}$ & $\begin{array}{l}(0.008) \\
-0.001\end{array}$ & $\begin{array}{l}(0.001) \\
0.015^{* *}\end{array}$ & $-0.013^{+*}$ \\
\hline & $(0.038)$ & $(0.002)$ & $(0.003)$ & $(0.019)$ & $(0.001)$ & $(0.002)$ \\
\hline RURALIDAD & $\begin{array}{c}-0.002 \\
(0.002)\end{array}$ & $\begin{array}{c}0.001^{*+*} \\
(0.000)\end{array}$ & $\begin{array}{l}0.003^{* 6 *} \\
(0.000)\end{array}$ & $\begin{array}{c}0.004^{* * 4} \\
(0.001)\end{array}$ & $\begin{array}{c}-0.003^{* * *} \\
(0.000)\end{array}$ & $\begin{array}{c}0.001^{*} * 4 \\
(0.000)\end{array}$ \\
\hline IPP_HABITANT & $\begin{array}{c}-2.14 \mathrm{e}-08 * 44 \\
(5.88 \mathrm{e}-09)\end{array}$ & $\begin{array}{c}3.31 \mathrm{e}-094 * 4 \\
(3.03 e-10)\end{array}$ & $\begin{array}{c}-6.33 \mathrm{e}-09 * 4 * \\
(4.22 \mathrm{e}-10)\end{array}$ & $\begin{array}{c}0 \\
(2.69 \mathrm{e}-09)\end{array}$ & $\begin{array}{c}-1.25 e-09 * 4 * \\
(2.41 \mathrm{e}-10)\end{array}$ & $\begin{array}{c}-8.37 e-10 * 4 \\
(3.48 e-10)\end{array}$ \\
\hline DIA LUNES & $\begin{array}{c}-0.988^{4 * 4} \\
(0.184)\end{array}$ & $\begin{array}{c}0.252^{* * *} \\
(0.020)\end{array}$ & $\begin{array}{c}-0.521^{* * *} \\
(0.019)\end{array}$ & $\begin{array}{l}-0.072 \\
(0.118)\end{array}$ & $\begin{array}{c}0.255^{* * *} \\
(0.014)\end{array}$ & $\begin{array}{c}0.264^{* * *} \\
(0.018)\end{array}$ \\
\hline DIA_MARTES & $-0.766^{* * * 4}$ & $0.378^{* 4 *}$ & $-0.469 * 64$ & -0.169 & $0.230^{\circ * 4}$ & $0.223^{* 4 *}$ \\
\hline DIA_MIERCOLES & $\begin{array}{c}(0.171) \\
-1.048^{* * *} \\
(0.188)\end{array}$ & $\begin{array}{l}(0.020) \\
0.344^{* * 4 *}\end{array}$ & $\begin{array}{c}(0.019) \\
-0.409^{* * *} \\
(0.019)\end{array}$ & $\begin{array}{l}(0.123) \\
-0.037 \\
(0.118)\end{array}$ & $\begin{array}{l}(0.014) \\
0.222 * * * \\
(0.014)\end{array}$ & $\begin{array}{c}(0.018) \\
0.193^{*+*} \\
(0.018)\end{array}$ \\
\hline DIA_JUEVES & $\begin{array}{c}-0.986^{\circ * 4} \\
(0.184)\end{array}$ & $\begin{array}{c}0.364^{* * 4} \\
(0.020)\end{array}$ & $\begin{array}{c}-0.403 * 4 \\
(0.019)\end{array}$ & $\begin{array}{l}0.0327 \\
(0.117)\end{array}$ & $\begin{array}{c}0.216^{* 4 *} \\
(0.014)\end{array}$ & $\begin{array}{c}0.181^{* * *} \\
(0.018)\end{array}$ \\
\hline DIA VIERNES & $\begin{array}{c}-0.576^{4 * 4} \\
(0.160)\end{array}$ & $\begin{array}{c}0.385 * * 4 \\
(0.020)\end{array}$ & $\begin{array}{c}-0.404^{4}+4 \\
(0.018)\end{array}$ & $\begin{array}{c}0.159 \\
(0.112)\end{array}$ & $\begin{array}{c}0.179 * 4 * \\
(0.014)\end{array}$ & $\begin{array}{l}0.222 * * * \\
(0.018)\end{array}$ \\
\hline DIA SABADO & $\begin{array}{c}-0.669 * * 4 \\
(0.166)\end{array}$ & $\begin{array}{l}0.243^{* * *} \\
(0.020)\end{array}$ & $\begin{array}{c}-0.169 * * 4 \\
(0.018)\end{array}$ & $\begin{array}{l}0.260^{\circ *} \\
(0.108)\end{array}$ & $\begin{array}{c}0.018 \\
(0.015)\end{array}$ & $\begin{array}{l}0.129 * * * \\
(0.019)\end{array}$ \\
\hline DMES_ENERO & $\begin{array}{l}0.487 * * \\
(0.211)\end{array}$ & $\begin{array}{c}0.122 * * * \\
(0.024)\end{array}$ & $\begin{array}{c}0.002 \\
(0.024)\end{array}$ & $\begin{array}{c}0.062 \\
(0.151)\end{array}$ & $\begin{array}{c}-0.092^{* * *} \\
(0.018)\end{array}$ & $\begin{array}{c}0.011 \\
(0.023)\end{array}$ \\
\hline DMES_FEBRERO & $\begin{array}{c}0.214 \\
(0.232)\end{array}$ & $\begin{array}{c}0.149 * * * * \\
(0.025)\end{array}$ & $\begin{array}{c}-0.108^{* * *} \\
(0.026)\end{array}$ & $\begin{array}{c}0.085 \\
(0.157)\end{array}$ & $\begin{array}{c}-0.055^{* * *} \\
(0.019)\end{array}$ & $\begin{array}{l}0.055^{\circ *} \\
(0.024)\end{array}$ \\
\hline DMES MARZO & $\begin{array}{c}-0.197 \\
(0.246)\end{array}$ & $\begin{array}{c}0.164 * * 4 \\
(0.024)\end{array}$ & $\begin{array}{c}-0.008 \\
(0.024)\end{array}$ & $\begin{array}{c}0.224 \\
(0.147)\end{array}$ & $\begin{array}{c}-0.107^{4}+4 \\
(0.018)\end{array}$ & $\begin{array}{c}0.006 \\
(0.023)\end{array}$ \\
\hline DMES ABRII & $\begin{array}{c}-0.386 \\
(0.264)\end{array}$ & $\begin{array}{c}0.146^{* * 4} \\
(0.024)\end{array}$ & $\begin{array}{l}-0.058^{* *} \\
(0.025)\end{array}$ & $\begin{array}{c}0.016 \\
(0.158)\end{array}$ & $\begin{array}{c}-0.048^{*-4} \\
(0.018)\end{array}$ & $\begin{array}{c}0.032 \\
(0.023)\end{array}$ \\
\hline DMES_MAYO & $\begin{array}{l}-0.098 \\
(0.242)\end{array}$ & $\begin{array}{l}0.159 * * 4 \\
(0.024)\end{array}$ & $\begin{array}{c}-0.137 * 4 \\
(0.025)\end{array}$ & $\begin{array}{r}-0.055 \\
(0.158)\end{array}$ & $\begin{array}{l}-0.007 \\
(0.018)\end{array}$ & $\begin{array}{c}0.063^{* * 4} \\
(0.023)\end{array}$ \\
\hline DMES_תNIO & $\begin{array}{c}-0.580^{* *} \\
(0.284)\end{array}$ & $\begin{array}{l}0.162 * 4 * \\
(0.024)\end{array}$ & $\begin{array}{c}-0.162^{* * 4} \\
(0.025)\end{array}$ & $\begin{array}{c}0.127 \\
(0.154)\end{array}$ & $\begin{array}{c}0.024 \\
(0.018)\end{array}$ & $\begin{array}{c}0.083^{* 4 *} \\
(0.023)\end{array}$ \\
\hline DMES RULO & $\begin{array}{l}-0.144 \\
(0.250)\end{array}$ & $\begin{array}{c}0.178^{* 4 *} \\
(0.024)\end{array}$ & $\begin{array}{c}-0.269 * 4 \\
(0.026)\end{array}$ & $\begin{array}{r}-0.154 \\
(0.165)\end{array}$ & $\begin{array}{c}0.0384^{4 *} \\
(0.018)\end{array}$ & $\begin{array}{c}0.134^{* * 4} \\
(0.023)\end{array}$ \\
\hline DMES AGOSTO & $\begin{array}{l}-0.515^{\circ} \\
(0.268)\end{array}$ & $\begin{array}{l}0.172 * 4 \% \\
(0.024)\end{array}$ & $\begin{array}{c}-0.208^{4 * 4} \\
(0.025)\end{array}$ & $\begin{array}{c}0.000 \\
(0.155)\end{array}$ & $\begin{array}{c}0.026 \\
(0.018)\end{array}$ & $\begin{array}{c}0.099 * * * \\
(0.023)\end{array}$ \\
\hline DMES_SEPTIEMIBRE & $\begin{array}{r}-0.147 \\
(0.245)\end{array}$ & $-0.055^{5}$ & $-0.109 * 4$ & 0.093 & $0.085^{* * *}$ & $0.098^{* 64}$ \\
\hline $\begin{array}{l}\text { DMES_OCTUBRE } \\
\text { DMES_NOVIEMBRE }\end{array}$ & $\begin{array}{c}(0.245) \\
-0.200 \\
(0.242) \\
-0.031 \\
(0.232)\end{array}$ & $\begin{array}{c}-0.012 \\
(0.024) \\
-0.022 \\
(0.024)\end{array}$ & $\begin{array}{c}(0.02 .5) \\
-0.039 \\
(0.024) \\
-0.035 \\
(0.024)\end{array}$ & $\begin{array}{c}(0.154) \\
-0.236 \\
(0.163) \\
0.112 \\
(0.150)\end{array}$ & $\begin{array}{c}(0.018) \\
-0.013 \\
(0.018) \\
-0.015 \\
(0.018)\end{array}$ & $\begin{array}{c}(0.025) \\
0.134^{* * 4} \\
(0.022) \\
0.114^{* * 4} \\
(0.022)\end{array}$ \\
\hline DLUGAR VIA PUBLICA & $\begin{array}{l}0.772^{* * *} \\
(0.177)\end{array}$ & $\begin{array}{c}-1.734^{* * 4} \\
(0.013)\end{array}$ & $\begin{array}{l}0.252 * * * \\
(0.014)\end{array}$ & $\begin{array}{l}-0.762 * 4 * \\
(0.108)\end{array}$ & $\begin{array}{l}-0.254^{* * *} \\
(0.010)\end{array}$ & $\begin{array}{c}1.837 * * * \\
(0.016)\end{array}$ \\
\hline DLUGAR_PARQUE_ENTRETENCIO & $1.700^{\circ}$ & $-0.396^{\circ *}$ & $1.007^{* 4 *}$ & -.. & $-0.814^{* * *}$ & $\begin{array}{c}(0.029) \\
1.045^{*+4}\end{array}$ \\
\hline DLUGAR_DISCOTTEQUE & $\begin{array}{c}(1.018) \\
0.687 \\
(1.016)\end{array}$ & $\begin{array}{l}(0.161) \\
0.377^{* * 4} \\
(0.085)\end{array}$ & $\begin{array}{c}(0.149) \\
1.539 * 4 * \\
(0.084)\end{array}$ & $\begin{array}{c}0 . \overline{540} \\
(0.585)\end{array}$ & $\begin{array}{c}(0.165) \\
-2.283 * 4 \% \\
(0.163)\end{array}$ & $\begin{array}{l}(0.175) \\
0.00431 \\
(0.159)\end{array}$ \\
\hline DLUGAR VIGILADO & $\begin{array}{c}0.254 \\
(1.016)\end{array}$ & $\begin{array}{c}1.396^{* * 4} \\
(0.069)\end{array}$ & $\begin{array}{c}-1.709 * 4 \% \\
(0.184)\end{array}$ & $\begin{array}{l}-1.066 \\
(1.004)\end{array}$ & $\begin{array}{c}-0.575^{* * *} \\
(0.075)\end{array}$ & $\begin{array}{c}-0.352^{4 *} \\
(0.140)\end{array}$ \\
\hline DLUGAR_LOCALES_COMERCIALES & $-1.718^{*+*}$ & $2.252^{* * 4}$ & $-1.700^{*} * 4$ & $-3.511 * * 4$ & $-1.786^{* * 4}$ & $-0.623 * 4$ \\
\hline DLUGAR SERUTCFNTRO & $(0.527)$ & $(0.016)$ & $(0.034)$ & $(0.583)$ & $(0.018)$ & $(0.030)$ \\
\hline DLUGAR_SERVICENIRO & $\begin{array}{l}-1.338 \\
(1.014)\end{array}$ & $\begin{array}{c}0.137^{464} \\
(0.034)\end{array}$ & $\begin{array}{c}-1.750^{404} \\
(0.087)\end{array}$ & $\ldots$ & $\begin{array}{c}-1.128^{4 * 4} \\
(0.040)\end{array}$ & $\begin{array}{l}2.339 * 4 \% \\
(0.034)\end{array}$ \\
\hline DLUGAR_VEH_LOCOMOCION & $\overline{-}$ & $\begin{array}{c}-0.229 * * 4 \\
(0.027)\end{array}$ & $\begin{array}{c}-0.675^{* * 4} \\
(0.044)\end{array}$ & $\begin{array}{c}-2.473 * * * \\
(0.712)\end{array}$ & $\begin{array}{c}-5.026^{4 * 4} \\
(0.172)\end{array}$ & $\begin{array}{c}3.007^{* * 4} \\
(0.028)\end{array}$ \\
\hline DLUGAR SUPERMERCADO & - & $2.880^{\circ * 4 *}$ & $-1.843^{*+*}$ & $\ldots$ & $-2.168^{4 * 4}$ & $-1.313+4$ \\
\hline & - & $(0.019)$ & $(0.034)$ & $\ldots$ & $(0.022)$ & $(0.037)$ \\
\hline DLUGAR FARMACTA & - & $1.073 * 64$ & -2.333404 & -- & $-1.395 * 4$ & $1.326^{* * 4 *}$ \\
\hline & - & $(0.048)$ & $(0.198)$ & $\ldots$ & $(0.063)$ & $(0.057)$ \\
\hline DLUGAR_METRO & - & $0.622^{*+4}$ & $0.488^{-46}$ & $-2.058^{40}$ & $-3.996^{* 64}$ & $1.571^{* 64}$ \\
\hline Constant & $\begin{array}{c}-7 . \overline{-} \\
(0.318)\end{array}$ & $\begin{array}{c}(0.038) \\
-1.344^{* * * *} \\
(0.030)\end{array}$ & $\begin{array}{c}(0.051) \\
-1.582^{\star * \star *} \\
(0.031)\end{array}$ & $\begin{array}{l}(1.004) \\
-6.581^{* \pm *} \\
(0.198)\end{array}$ & $\begin{array}{c}(0.158) \\
0.169^{ \pm \pm *} \\
(0.023)\end{array}$ & $\begin{array}{c}(0.044) \\
-3.179 * \pm * \\
(0.031)\end{array}$ \\
\hline Obserrations & 326,513 & 374,751 & 374,751 & 332,510 & 374,751 & 374,751 \\
\hline
\end{tabular}

La variable "densidad" poblacional afecta significativamente la probabilidad de delito solo en los casos de violación, robo con violencia (ambos con efecto positivo) y robo con fuerza

${ }^{25}$ Las estimaciones son Log-Likelihood 
(efecto negativo). El signo negativo antes mencionado se explica por la naturaleza del delito, en el cual se tipifica en el código penal como aquel en el cual hay algún tipo de ingreso forzoso a una propiedad, usualmente una casa, hecho más probable en zonas con baja densidad poblacional. Por su parte el "hacinamiento" afecta positiva y significativamente la probabilidad de Homicidios, Lesiones, Violación y Robo con Violencia. Ello es compatible con la naturaleza de tales delitos, toda vez que estos suelen ocurrir en espacios cerrados, en los cuales los problemas de hacinamiento pueden llegar a transformarse en un severo problema de convivencia. La incidencia negativa y significativa de las áreas verdes en los casos de Lesiones y Robo con Violencia, refuerza la hipótesis de que la mayor disponibilidad de espacios abiertos (áreas verdes), reduce la probabilidad de contactos indeseados entre individuos y por lo tanto de agresiones físicas entre ellos. Una vez más, en los casos de Hurto y Robo con Fuerza, el efecto positivo de las áreas verdes responde al tipo de comunas en las cuales tales delitos son más comunes, siendo usualmente aquellas con mayor número de viviendas de alto valor y mayor extensión de áreas verdes. Es interesante constatar que la condición de ruralidad aumenta la probabilidad de delito en todas las categorías con excepción de los Homicidios y los Robos con Fuerza. Lo anterior podría explicarse en función de un menor resguardo a los derechos de propiedad en zonas rurales versus la ciudad, hecho que se expresa en mayor facilidad de acceso de extraños a recintos privadas y baja presencia de moradores. Relativamente, la presencia policial es precaria en zonas rurales, lo cual facilita el delito de Violación y de Lesiones (efecto positivo). El efecto negativo del IPP por habitante es indicativo de que las zonas más desprotegidas son aquellas con menor presencia de una autoridad local que asuma problemas colectivos en forma sistémica, en lo cual se incluye la propia infraestructura pública. En dicho espíritu, la referida variable es una proxy del grado en el cual el Estado, a través del municipio, representa los intereses de la comunidad y la compromete con el respeto a la norma y al Estado de derecho.

A partir de la misma tabla $\mathrm{n}^{\mathbf{0}} 2$ podemos observar la incidencia de las variables temporales. En el caso de los Homicidios, el signo negativo y significativo de las variables mudas entre lunes y sábado, sugiere que es el día domingo en el cuál hay mayor probabilidad de homicidios (el día omitido en la regresión) ${ }^{26}$. Igual razonamiento cabe respecto de los meses. Al ser diciembre el mes omitido, los efectos significativos de los restantes meses deben evaluarse en comparación a dicho mes. Ello implica que el mes de enero registra mayor probabilidad de homicidios, mientras que junio y agosto registran menor probabilidad. La misma lectura respecto de los Hurtos, indica que los días domingos hay menor probabilidad de dicho delito, que los meses de enero a septiembre registran mayor número de casos, y que la probabilidad de ocurrencia en septiembre es menor. El día con menos probabilidad de Hurtos sería el domingo. Respecto del delito de Lesiones, todos los días consignados registran menor probabilidad de ocurrencia respecto del domingo. Efecto negativo y significativo sobre su probabilidad de ocurrencia se observa en los casos de febrero, abril, mayo, junio, julio, agosto y septiembre. En cuanto al delito de Violación, solo el día sábado aparece con mayor probabilidad de ocurrencia, no habiendo ningún mes específico con impacto significativo. El Robo con Fuerza muestra una mayor probabilidad de lunes a viernes, y en los meses de julio y septiembre. Finalmente el Robo con Violencia

\footnotetext{
${ }^{26}$ Las variables mudas incluidas deben ser igual al número características (días o meses) menos uno.
} 
CADENA, Pablo; LETELIER, Leonardo. "Determinantes de los Delitos de Mayor Connotación Social en la Región Metropolitana. Análisis en base a un modelo de regresión logística".

exhibe menor probabilidad el día domingo y los meses de febrero, mayo, junio, julio, agosto, septiembre, octubre y noviembre.

El primer aspecto a observar es que los delitos usualmente no ocurren en el domicilio, salvo en el caso de las violaciones. Los parques de entretenimiento inciden positivamente en los casos de Homicidios, delitos con Lesiones, y Robo con Violencia. Esperablemente, las discotecas son escenarios de Hurtos y Lesiones, toda vez que concentran numerosos individuos en espacios cerrados y pequeños. Los lugares vigilados registran en general menor probabilidad de delitos, salvo en el caso de Hurtos. El signo positivo en este caso puede reflejar un sesgo de simultaneidad, toda vez que los lugares más afectados por hurto tienden a tener más vigilancia. Los locales comerciales exhiben menor probabilidad de ocurrencia en todos los casos, con excepción de los Hurtos, los cuales ocurren con más frecuencia en tales lugares. Los servicentros son escenarios más frecuentes de Hurtos y Robos con Fuerza. Los supermercados y farmacias tienen un patrón semejante en todos los delitos, con excepción del Robo con Violencia, que afecta positivamente a las farmacias y negativamente a los supermercados. Esto último puede ser fácilmente explicado por la facilidad de acceso a las farmacias, y la facilidad de escapar por parte de los delincuentes, lo cual no suele ser el caso en supermercados. El metro, finalmente, exhibe nula ocurrencia de homicidios, pero una significativa incidencia de Hurtos, Lesiones y Robo con Violencia. Una vez más en este caso, la concentración de personas en espacios cerrados y pequeños facilita este tipo de delitos.

\subsection{Análisis de Gráfico ${ }^{27}$}

Al obtener el valor estimado de la probabilidad a partir de las regresiones logísticas de la tabla $n^{\circ} 2$, se obtiene el análisis gráfico presentado a continuación. Esta estimación se realizó al valor promedio de todas las variables explicativas en cada modelo.

De la observación del gráfico $n^{\circ} 1$, es posible establecer que la probabilidad de ocurrencia de un delito de homicidio es significativamente mayor en las comunas de La Pintana, Cerro Navia y San Ramón. Por el contrario, las comunas del sector nororiente de la Región, como son Las Condes, Providencia y Vitacura, presentan la menor probabilidad de que suceda el delito observado. La explicación de este fenómeno se encuentra validada a nivel internacional. Comunas de mayor ingreso promedio y residentes más homogéneos en términos de ingreso, exhiben menor ocurrencia de muertes intencionales causadas por terceros.

${ }^{27}$ Gráficos de las predicciones condicionadas obtenidas de las regresiones de la tabla $\mathrm{n}^{\circ} 4$ 
Polit. crim. Vol. 13, № 26 (Diciembre 2018) Art. 12, pp. 1170-1189.

[http://www.politicacriminal.cl/Vol_13/n_26/Vol13N26A12.pdf]

\section{Gráfico no 1 Delito de homicidio}

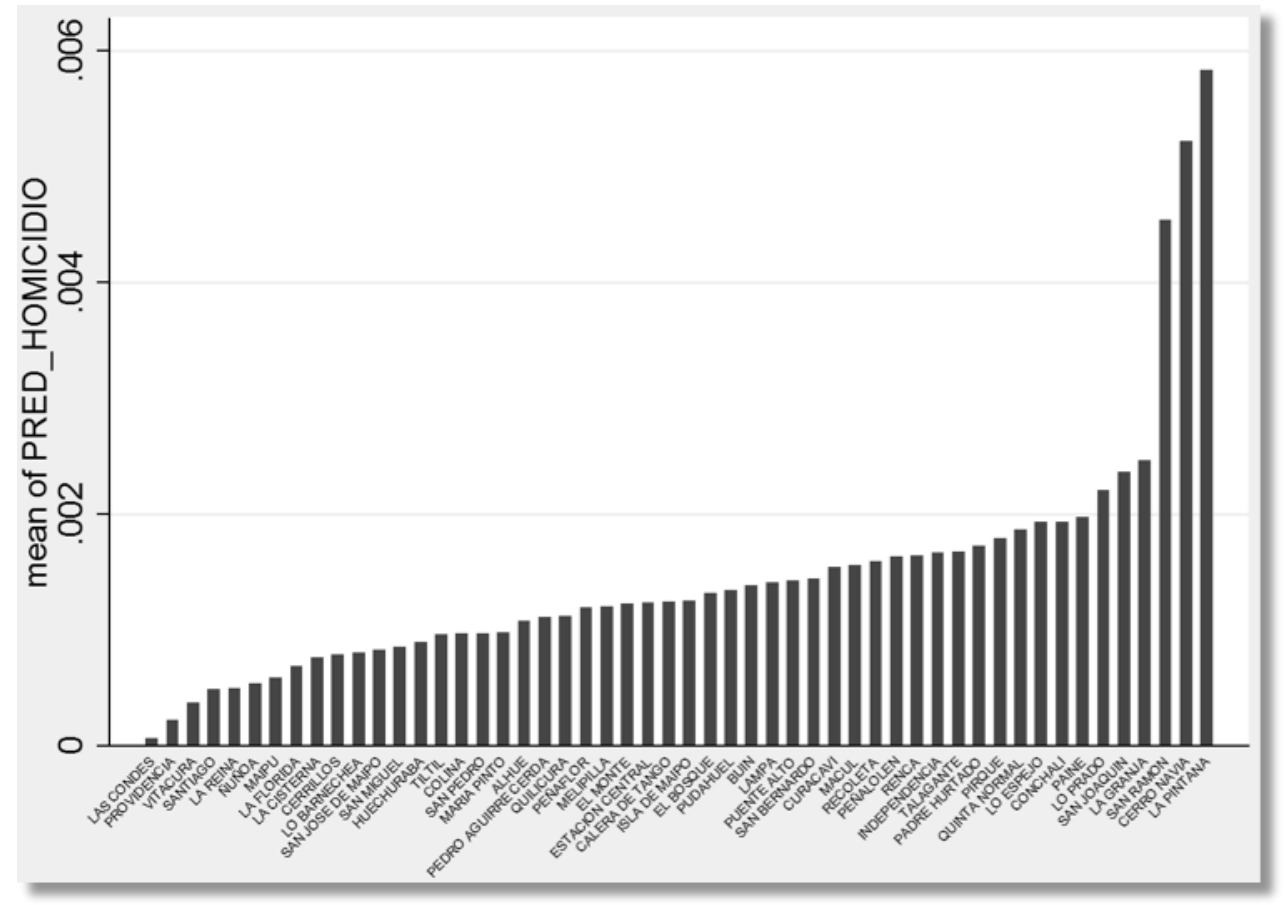

El gráfico $\mathrm{n}^{\circ} 2$, muestra la probabilidad de ocurrencia del delito de Hurto en las comunas de la Región Metropolitana, siendo más probable en Las Condes, Cerrillos y La Florida. La situación opuesta se observa en las comunas de Cerro Navia, Lo Espejo y La Granja.

\section{Gráfico no 2 Delito de hurto}

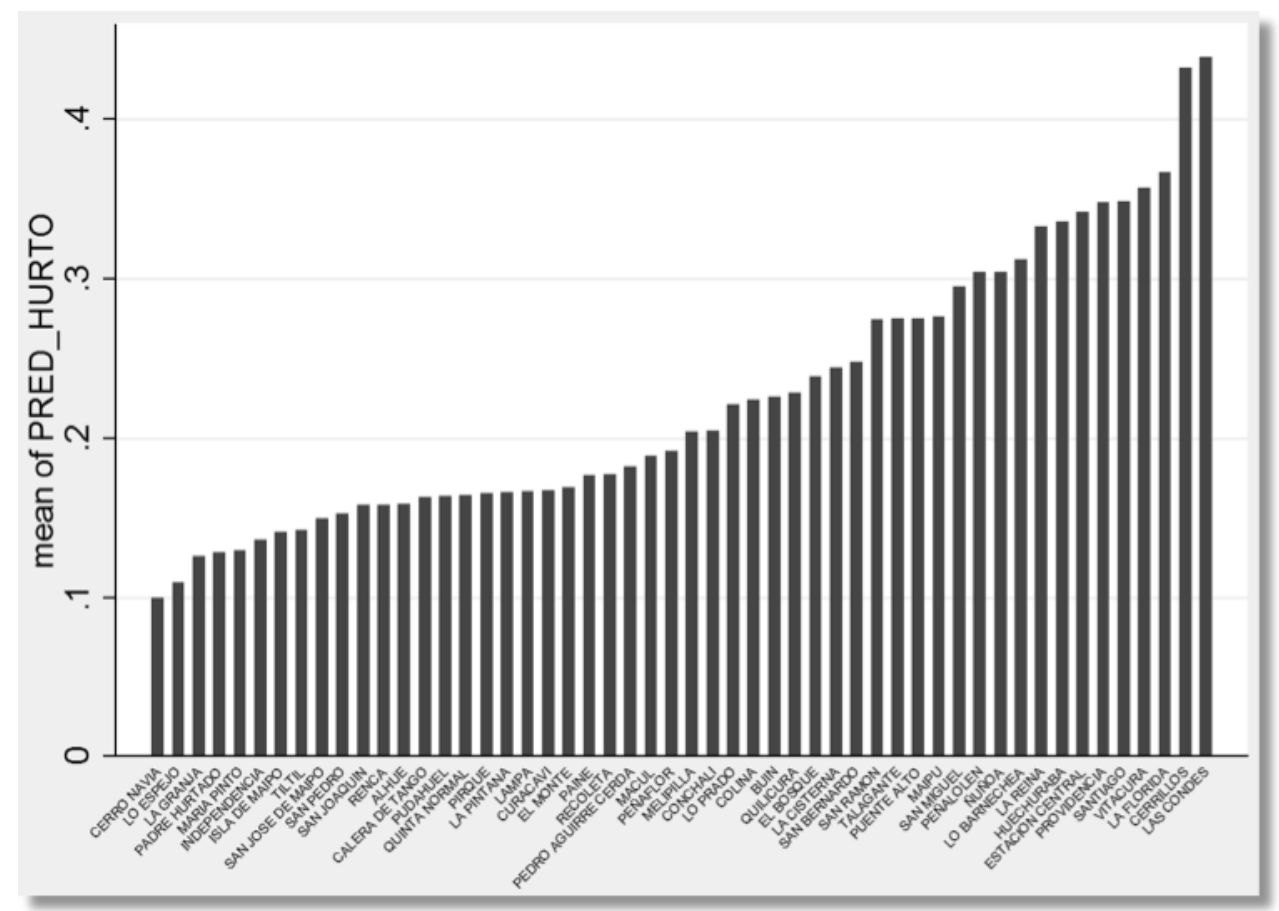


CADENA, Pablo; LETELIER, Leonardo. "Determinantes de los Delitos de Mayor Connotación Social en la Región Metropolitana. Análisis en base a un modelo de regresión logística".

El delito de Hurto es típicamente un "delito de oportunidad"28. Al respecto, se debe tener en consideración que podemos estar hablando de delitos denunciados en una comuna distinta a aquella donde tuvieron lugar los hechos, pues el denunciante puede darse cuenta horas después de haber sido víctima, concurriendo en ese caso a la unidad policial más cercana, la cual no necesariamente es la que corresponde al sector donde ocurrió el ilícito. Muchos Hurtos ocurren durante el trayecto en la locomoción colectiva (microbuses y red de Metro), lo que podría explicar que la comuna de Las Condes se ubique entre las más victimizadas. Otra vertiente de ocurrencia es en lugares donde se concentran personas en forma masiva, como grandes espectáculos, centros comerciales, etc. (factor relevante en la teoría de las oportunidades delictivas). En comunas como Las Condes y La Florida, se encuentran numerosos centros comerciales, que en sus horas de mayor afluencia de público generan oportunidades atractivas tanto para hurtar al público como a las tiendas que allí se ubican. En el caso de la comuna de Cerrillos, el problema del llamado "robo hormiga" puede parecer inocuo, pero genera enormes pérdidas para el comercio a nivel agregado.

Se puede apreciar del gráfico $\mathrm{n}^{\circ} 3$, que la probabilidad de ocurrencia de delitos de Lesiones es mayor en las comunas de Cerro Navia, La Pintana y San Pedro; y visiblemente menor en las comunas ubicadas en el sector nororiente de la Región, como son Las Condes y Providencia, seguido de La Reina.

\section{Gráfico no 3 Delito de lesiones}

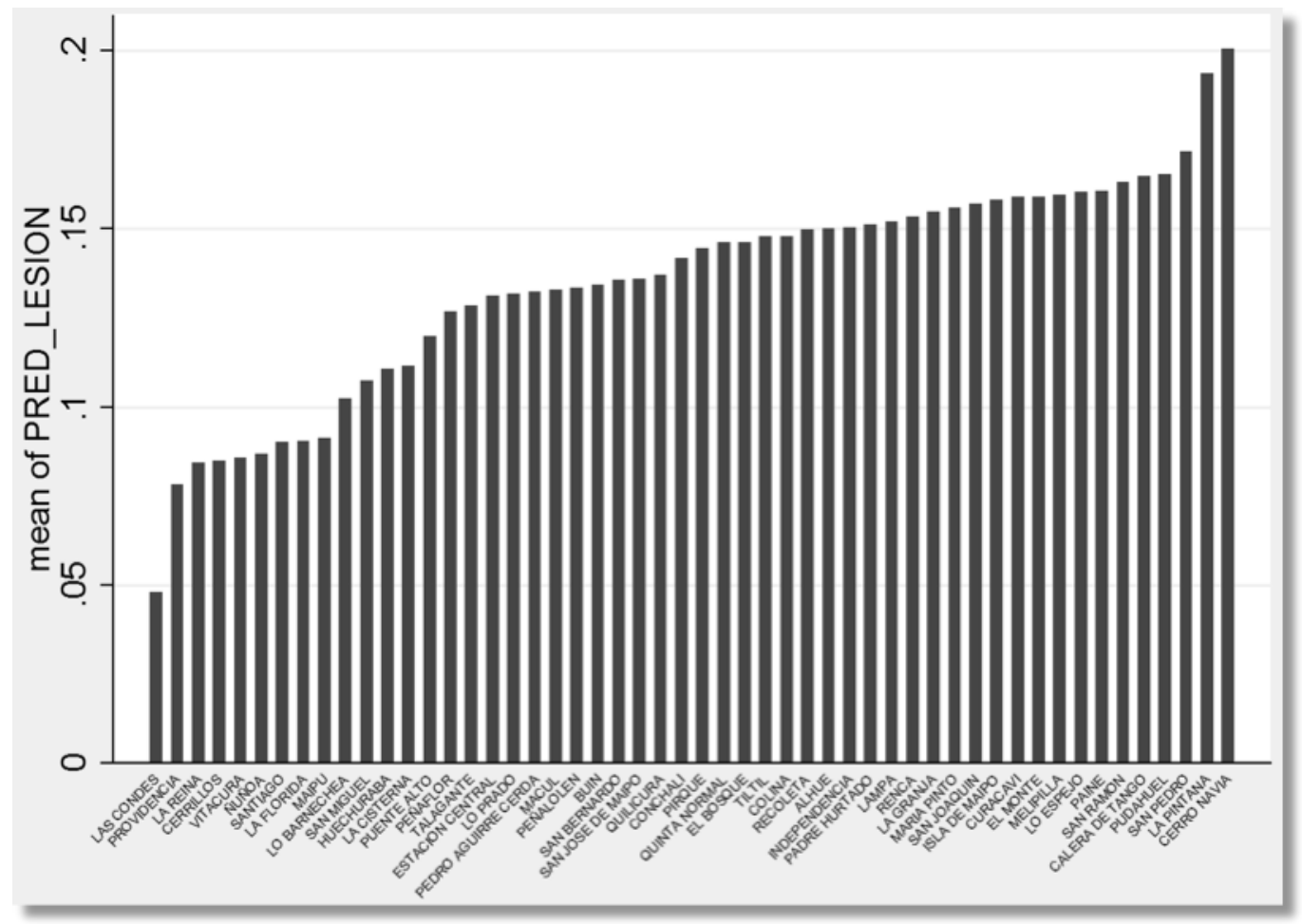

${ }^{28}$ FELSON, Marcus, y CLARKE, Ronald V. G. "Opportunity makes the thief: Practical theory for crime prevention", Home Office, Policing and Reducing Crime Unit, Research, Development and Statistics Directorate, Vol. 8, 1998. 
Algo similar ocurre en el caso de los Homicidios. Estos se concentra en comunas con mayores niveles de violencia, y pueden estar asociados tanto a disputas interpersonales (o de convivencia) como a la mayor presencia de actividad delictiva ${ }^{29}$. En nuestro país sigue predominando el primer tipo de violencia (interpersonal) por sobre el segundo (delictiva), pero éste último ha ido al alza en los últimos años, volviéndose de mayor impacto al incorporar el uso de armas de fuego en su comisión. En el caso de las comunas de Cerro Navia y La Pintana, podemos observar este aumento de la violencia asociada a delitos como el narcotráfico. En torno a esta actividad surgen bandas que se disputan territorios, realizan quitadas de drogas o "mexicanas" y amedrentan tanto a sus rivales como a la población en general. La violencia de convivencia se relaciona fuertemente al consumo de alcohol que desemboca en agresiones o riñas.

A partir del gráfico $\mathrm{n}^{\circ} 4$, se evidencia que la comuna de Cerro Navia es la que presenta mayor probabilidad de ocurrencia del delito de Violación, seguida por La Pintana y San Ramón. En el extremo opuesto se encuentran los casos de Vitacura, Las Condes y Providencia. A diferencia de los Homicidios, que pueden ser tanto intramuros como en lugares públicos, las Violaciones suelen producirse en espacios privados y supuestamente protegidos para las víctimas. Esto se explica porque la mayoría de los agresores tienen vínculos familiares o de algún tipo (conocidos, amigos, vecinos, etc.) con el agredido o la agredida. El comportamiento de este delito difiere en otras cosas con los dos anteriores tipos de delitos analizados, siendo alto también en países ricos ${ }^{30}$. En el caso de la Región Metropolitana, las comunas donde se concentra son aquellas de más bajos ingresos, las cuales tienen como factor común los altos niveles de hacinamiento y la precariedad de las viviendas en general, lo que fomenta situaciones de promiscuidad (familiares que comparten no solo habitaciones, sino también las camas). Otro factor, es que las redes que se establecen como soportes de quienes trabajan, hacen que muchas veces los niños queden al cuidado de adultos abusadores.

El Robo con Fuerza (gráfico 5), sugiere que las comunas con mayor probabilidad de incidencia son en general las de ingreso más alto (Vitacura, Las Condes, La Reina, Ñuñoa). Un perfil de ocurrencia diferente tiene el Robo con Violencia (gráfico 6) (Robo con Intimidación; Robo por Sorpresa; entre otros robos con violencia), el cual aparece como más probable en Lo Espejo, Cerro Navia y La Granja. Esta categoría incluye delitos contra la propiedad como también el robo por sorpresa y los delitos contra las personas como el Robo con Intimidación y el propio Robo con Violencia. Las comunas que concentran estos delitos coinciden en una baja inversión en infraestructura urbana (mobiliario, áreas verdes, pavimentos, luminarias, etc.). De ello se desprende que la estrategia de prevención situacional es vital para la disminución de estos delitos. Esta debe ser aplicada por las autoridades locales (municipios) y por las políticas públicas de nivel central (Ministerio de Vivienda, Ministerio de Obras Públicas y Ministerio de Bienes Nacionales, entre otros).

\footnotetext{
${ }^{29}$ KRUG Etienne, DAHLBERG Linda, MERCY, James, ZWI, Anthony y LOZANO, Rafael (Eds.), World report on violence and health. Ginebra, Organización Mundial de la Salud, 2002.

${ }^{30}$ Suecia se ubica en el segundo lugar mundial, siendo precedido solo por el Congo.
} 
CADENA, Pablo; LETELIER, Leonardo. "Determinantes de los Delitos de Mayor Connotación Social en la Región Metropolitana. Análisis en base a un modelo de regresión logística".

\section{Gráfico no 4 Delito de violación}

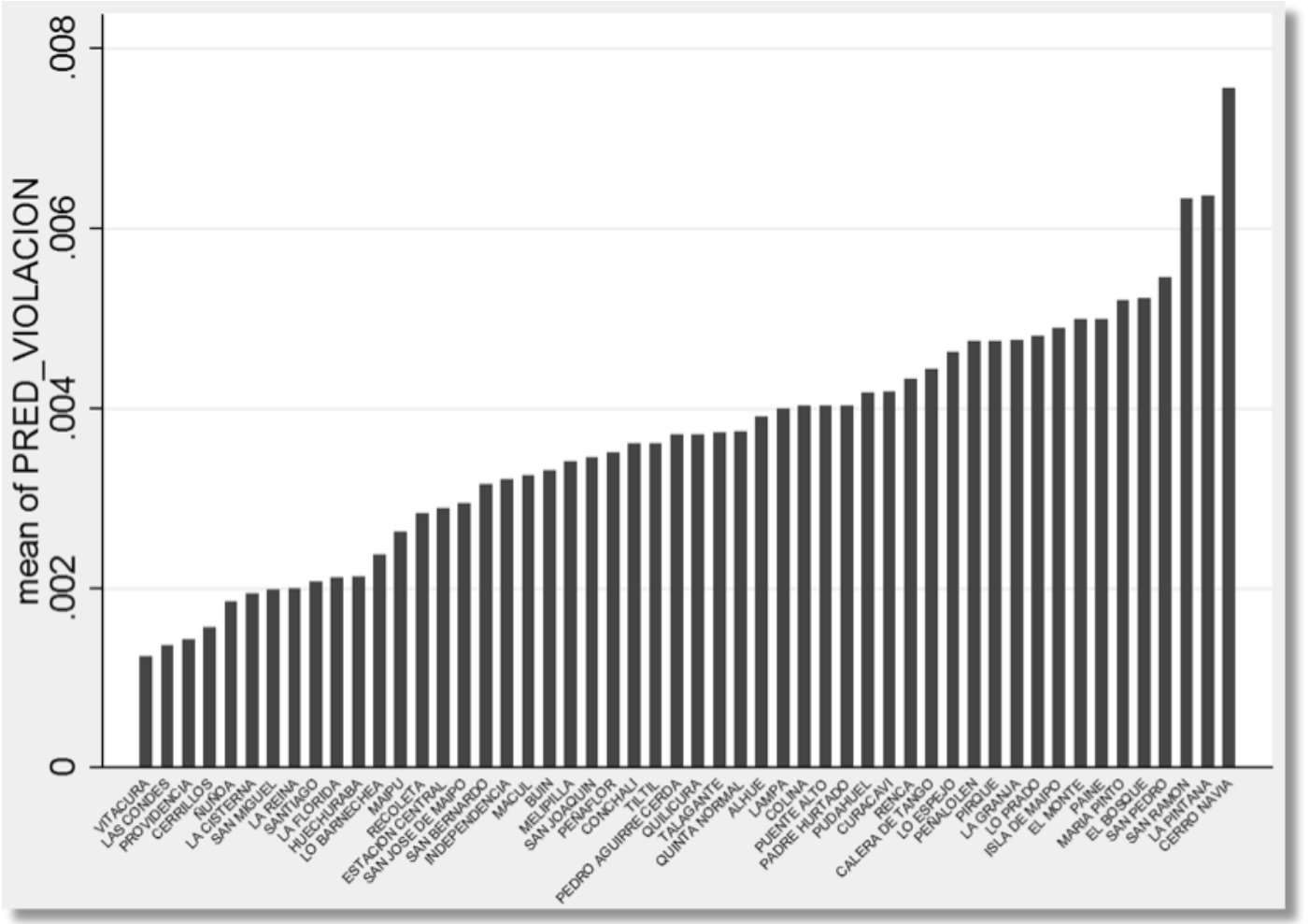

\section{Gráfico no 5 Delito de robo con fuerza}

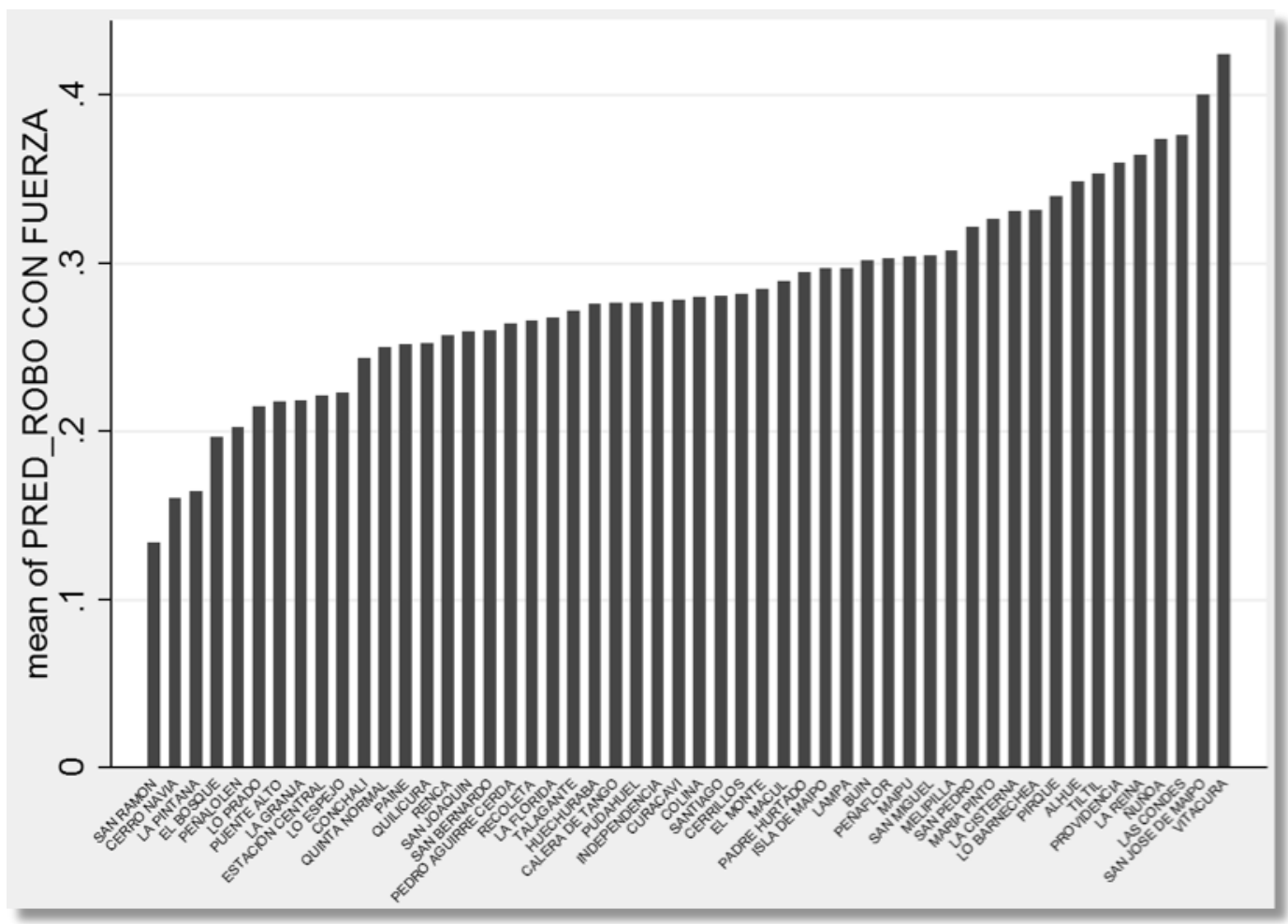




\section{Gráfico nº 6 Delito de robo con violencia}

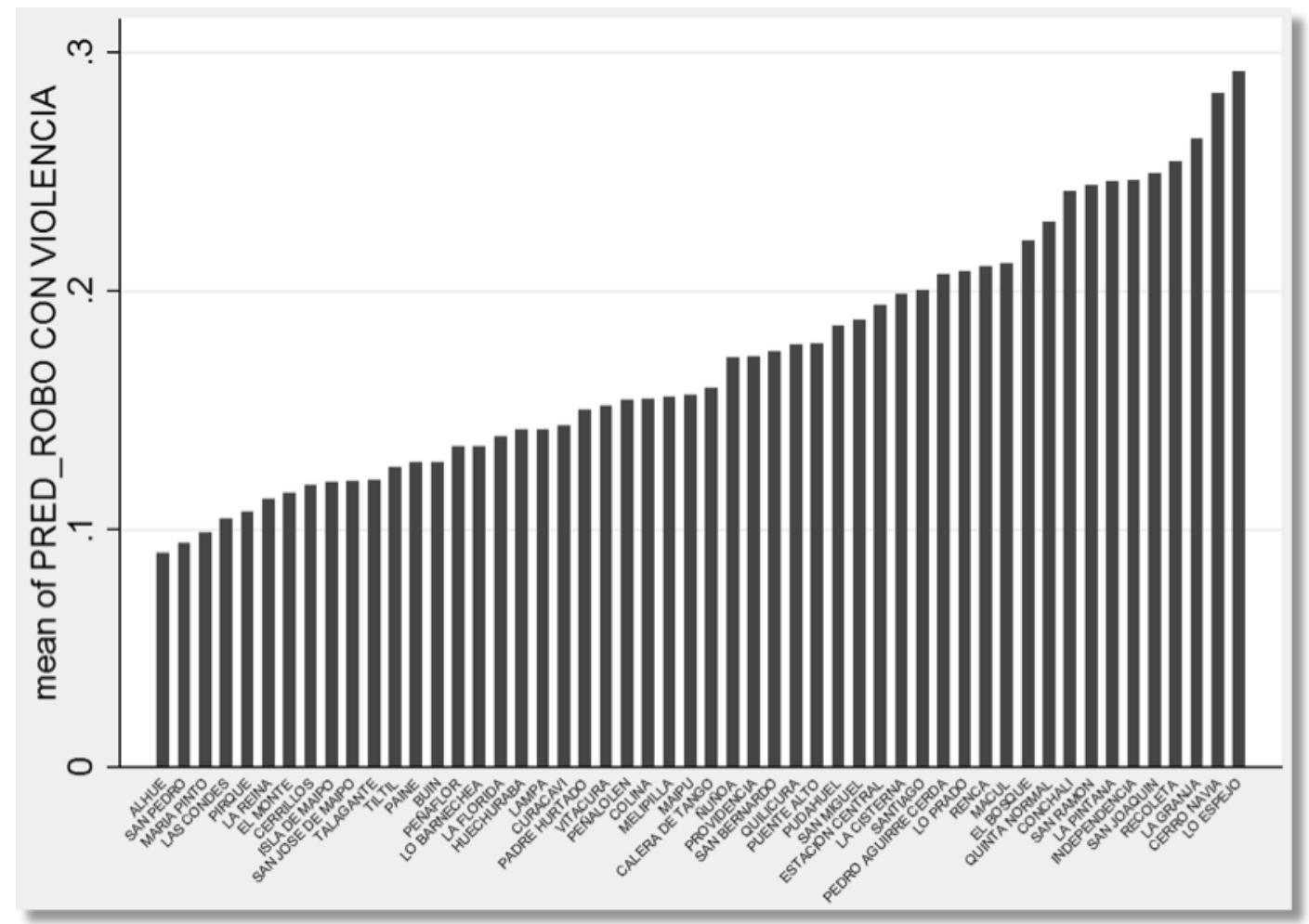

\section{Conclusiones}

El interés de llevar a cabo un estudio de estas características, es desarrollar herramientas que ayuden a caracterizar la probabilidad de ocurrencia de un acto criminal, en base a la información histórica disponible respecto de delitos que ya sucedieron. La modelación espacio-temporal de patrones criminales representa una inestimable fuente de información para las policías. Los modelos de incidentes delictuales no sólo permiten investigar y hacer análisis criminales, sino que además facilitan la predicción de la evolución de indicadores de riesgo en locaciones de interés específico. Si este tipo de modelos logra pronosticar dichos indicadores, las policías podrían entonces optimizar el despliegue de recursos con la consiguiente mejora en aspectos de seguridad y reducción de potenciales amenazas utilizando patrullajes preventivos y programas de vigilancia.

Los resultados derivados de las estimaciones del modelo logístico, permite corroborar diversas hipótesis en torno al origen del delito. Factores temporales, asociados a la fecha y día de ocurrencia, el lugar de ocurrencia y otros elementos de contexto, permiten anticipar la incidencia de delitos en lugares y momento específicos, todo lo cual colabora con el buen uso de los recursos policiales y la implementación de "patrullajes inteligentes". 
CADENA, Pablo; LETELIER, Leonardo. "Determinantes de los Delitos de Mayor Connotación Social en la Región Metropolitana. Análisis en base a un modelo de regresión logística".

\section{Bibliografía}

BECKER, Gary, "Crime and Punishment: An Economic Approach", Journal of Political Economy”, Vol. 76 (1968), pp.169-217.

BRANTINGHAM, Paul; BRANTINGHAM, Patricia, “Environmental Criminology”, Sage Publications, 1981.

DE LA PUENTE L., Patricio; TORRES R., Emilio, "Seguridad ciudadana y prevención del delito: un análisis crítico de los modelos y estrategias contra la criminalidad", Revista de Estudios Criminológicos y Penitenciarios, No 1 (2000), pp. 15-62.

DE LA FUENTE, Hanns; MEJÍAS, Claudia y CASTRO K., Pía, “Análisis econométrico de los determinantes de la criminalidad en chile", Política Criminal, vol. 6, no 11, doc. 1 (2011), pp. 192 - 208.

EHRLICH, Isaac, "Participation in illegitimate activities: A theoretical and empirical investigation", Journal of Political Economy, Vol. 81 (1973), pp. 521-565.

EIDE, Erling, "Economics of criminal behavior", Encyclopedia of Law and Economics 8100, 1999.

FELSON, Marcus, y CLARKE, Ronald V. G. "Opportunity makes the thief: Practical theory for crime prevention", Home Office, Policing and Reducing Crime Unit, Research, Development and Statistics Directorate, Vol. 8, 1998.

FLORES, Paulina, "Modelación y predicción de focos de criminalidad basada en modelos probabilísticos". Santiago, Chile: Universidad de Chile - Facultad de Ciencias Físicas y Matemáticas, 2014.

GUTIÉRREZ, Mauro, NÚÑEZ, Javier y RIVERA Jorge, “Caracterización socioeconómica y espacial de la criminalidad en Chile", Revista Cepal, no 98 (2009) pp. 165-180.

JOFRÉ, María Paz, "Análisis del fenómeno delictual utilizando un modelo de regresión logística en base a atributos". Santiago, Chile: Universidad de Chile - Facultad de Ciencias Físicas y Matemáticas, 2011.

KRUG Etienne, DAHLBERG Linda, MERCY, James, ZWI, Anthony y LOZANO, Rafael (Eds.), World report on violence and health. Ginebra, Organización Mundial de la Salud, 2002.

MOLINA, Oscar, NÚÑEZ, Javier, RIVERA, Jorge y VILLAVICENCIO, Xavier, "Determinantes Socioeconómicos y Demográficos del Crimen en Chile. Evidencia desde un panel de datos de las Regiones de Chile", Estudios de Economía № 30, (2003), pp. 55-85.

OBRECHT Ihl, Paz, "Predicción de crimen usando modelos de Markov ocultos". Santiago, Chile: Universidad de Chile - Facultad de Ciencias Físicas y Matemáticas, 2014.

RIVEROS, Luis, "El Enfoque Económico del Delito", Revista Académica de la Academia de Ciencias Policiales, Carabineros de Chile, no 47 (2008), pp. 25-38.

RUIZ, Paulina, CEA, Macarena, RODRÍGUEZ, Carlos, MATUS, Jean Pierre, "Determinantes de la criminalidad: Análisis de Resultados", Política Criminal, n³, Documento 1 (2007), pp.1-80.

TOLEDO, Rodrigo, "Métodos econométricos para el pronóstico de delitos en el gran Santiago". Santiago, Chile: Universidad de Chile - Facultad de Economía y Negocios, 2005. 
Polit. crim. Vol. 13, № 26 (Diciembre 2018) Art. 12, pp. 1170-1189.

[http://www.politicacriminal.cl/Vol_13/n_26/Vol13N26A12.pdf]

TRUDEL, Marcel; PUENTES-NEUMAN, Guadalupe, "The contemporary concepts of at risk children: theoretical models and approaches in the early years", Pan Canadian Education Research Agenda Symposium, 2000. 